\title{
A Review Paper on: Student Attendance System by Face Detection
}

\author{
Sneha D. Ikhar ${ }^{1}$, Sagar M. Bhakre ${ }^{2}$, Vaishali M. Bodhe \\ B.E, Dept of CSE, Ballarpur Institute of Technology, Ballarsha, Gondwana University (MS), India ${ }^{1,3}$ \\ Assistant Professor, Dept of CSE, Ballarpur Institute of Technology, Ballarsha, Gondwana University (MS), India ${ }^{2}$
}

\begin{abstract}
The face is the identity of a person. The method to exploit this physical feature have seen a great change since the advent of image processing techniques. The attendance is taken in every school, colleges and library. Traditional approach for attendance is professor calls student name \& record attendance. The system described in this paper aims to deviate from such traditional system and introduce a new approach for taking an attendance using image processing. This paper describes the working of An Automatic Attendance System in a classroom environment. There are several approaches to face recognition of which Principle Component Analysis (PCA) has been used extensively in literature. In this paper, Face Recognition based Automatic Attendance System using Principle Component Analysis is proposed. The system consists of a database of a set of facial patterns for individual. The characteristic features called 'Eigen Faces' are extracted from the stored images using which the system is trained for subsequent recognition of new images.
\end{abstract}

Keywords: Face Recognition, Face Detection, Principal Component Analysis (PCA), Eigen Face.

\section{INTRODUCTION}

Student attendance system is software developed for daily Data Flow Diagram:

student attendance in school, collages and institutes. If facilitates to access the attendance information of a particular student in a particular class. The information stored by the operator, which will be provided by the teacher for a particular class. The system will also help in evaluating attendance eligibility criteria of student.

Maintaining the attendance is very important and compulsory in all the institutes for checking the performance of student. Every institute has its own method in this regard. Some are taking attendance manually using the old paper old file based approach and some have adopted method of automatic attendance using some biometric techniques.

There are many automatic methods available forth is purpose i.e. RFID. All these method also waste time because student have to make a queue to touch their thumb on the scanning device.

The system is developed for deploying an easy and a secure way of taking down attendance. The software first captures an image of all the authorized student and stores the information into database.

The system then stores the image by mapping it into a face coordinate structure. The face detects by camera and scans that faces into database. Which student is present or face detect by camera that will be present in class otherwise absent student. That recorded into database and find total number of present student calculate and absent student will sending the message to student parent mobiles.

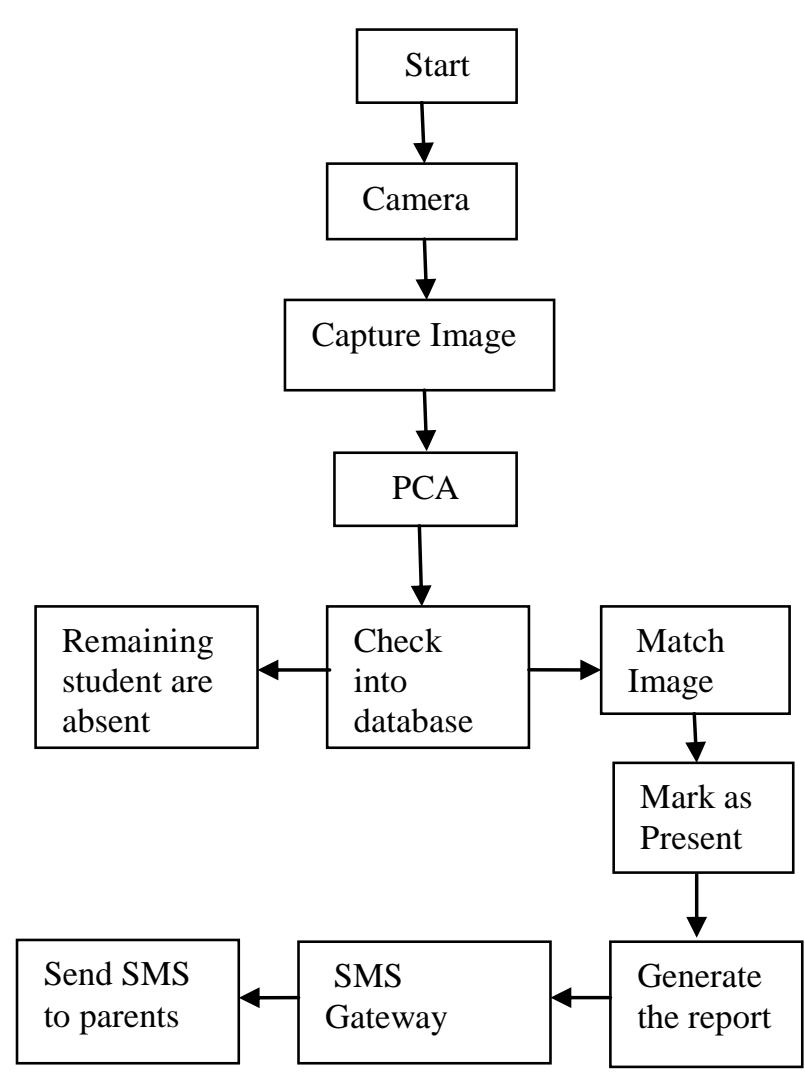

1.1 Face detection

Face detection section detect face from the image capture by the camera, and the image of the face is crop and store. The element recognizes the images of students face, which 
have been register manually with their names and enrollment no. in the record. Face detection data and face identification data are verification into the record. Automatic face recognition (AFR) technology has seen remarkable improvement in presentation over the past years, and such systems are now wide used for safety and marketable applications. An automatic system for face recognition in real time environment for collages to mark the attendance of their students.

\section{LITERATURE SURVEY}

K.Senthamil Selvi et.al. [1] "Face recognition based attendance marking system". In this projected work, sort to find the attendance, positions and face descriptions in classroom lecture, we projected the presence administration system based on face detection in the classroom lecture. The system estimates the presence and the location of each student by continuous inspection and footage. The result of our beginning experiment shows continuous inspection improved the performance for estimation of the attendance.

Mr.C.S.Patil et.al. [2] "Student Attendance Recording System Using Face Recognition with GSM Based". Student footage system using face validation was considered and implemented. It was tested with dissimilar face images. This idea is working properly with different panel. All windows are running separately and equivalent. If appreciation is to participate as a viable biometric for validation, then a further order for improvement in detection score is necessary. Under controlled condition, when lighting and pose can be controlled, this may be possible. It is more likely, that future improvement will rely on making better use of video knowledge and employing fully 3D face models.

Muhammad Fuzail et.al.[3] "Face Detection System for Attendance of Class Students". An regular attendance supervision system is a essential tool for any LMS. Most of the existing system are time consuming and necessitate for a semi instruction manual work from the instructor or students. This approach aim to explain the issues by integrates face detection on the procedure. Even though this method still lacks the capability to identify each student on class, there is a still much more room for enhancement. Since we implement a modular approach we can get better different module until we reach an acceptable detection an identification rate. Another issues that has to be taken in consideration in the opportunity is a process to ensure users privacy. Whenever you like a representation is stored on servers, it must be impossible for a person to use that image.

Mathana Gopala et.al. [4] "Implementation of Automated Attendance System using Face Recognition”. Automated presence system has been envision for the purpose of falling the errors that occur in conventional (manual) attendance taking system. The aim is to computerize and make a system that is useful to the institute such as an organization. The efficient and exact method of attendance in office atmosphere that can reinstate the old manual methods. This technique is secure enough, reliable and available for use. No need for dedicated hardware for installing the system in office. It can be constructed using a camera and computer.

\section{METHODOLOGY}

\subsection{PCA (Principle Component Analysis)}

PCA was invented in 1901 by Karl Pearson. Now it is mostly used as a tool in exploratory data analysis and for making predictive models (E.g face recognition). PCA is the simplest of the true eigenvector based multivariate analyses. Often, its operation can be through of as revealing the internal structure of the data in a way which best explain the variance (major features/ directions) in the data. If a multivariate dataset (e.g set of images) is visualized as a set of coordinates in a high-dimensional data space ( 1 axis per variable). Then PCA can supply the user with a lower-dimensional picture, a "shadow" of this object when viewed from its (in some sense) most informative viewpoint.

Principle Component Analysis (PCA) is a mathematical procedure that uses an orthogonal transformation convert a set of values of possibly correlated face images into a set of value of uncorrelated variable called eigen faces. The number of eigen faces always less than or equal to the number of original face images.

\subsection{Eigen Faces}

It is adequate and efficient method to be used in face recognition due to its simplicity, speed and learning capability. Eigen faces are a set of eigen vectors used in the computer vision problem of human face recognition. The eigen faces are principal of faces or equivalently. The eigen vectors of the covariance matrix of the set of the face images.

\section{FUTURE SCOPE}

The current recognition system has been designed for frontal views of face images. A neural network architecture (may be together with a feature based approach) can be implemented in which the orientation of the face is first determined, and then the most suitable recognition method is selected, also the current recognition system acquires face images only from face files located on magnetic mediums. Camera and scanner support should be implemented for greater flexibility.

\section{CONCLUSION}

This technique described the efficient and accurate method of automatic attendance in classroom environment that can replace the past manual methods. This novel method is secure enough, reliable and available for use. No need for 
Vol. 6, Issue 1, January 2017

specialized hardware for installing the system in the Vaishali M. Bodhe is student of Department of Computer classroom. It can be constructed using a camera and Science \& Engineering, Ballarpur Institute of Technology, computer. There is a need to use some algorithms that can Ballarsha, Gondwana University Gadhachiroli (MS), recognize the faces in well to improve the system India. Her interest in programming languages.

performance. This system is used for various application such as security purpose, industry, education, face recognition etc.

\section{REFERENCES}

[1] Aziza Ahmedi, Dr Suvarna Nandyal "An Automatic Attendance System Using Image Processing" The International Journal Of Engineering And Science (IJES) 2015 ISSN (e): 2319-1813 ISSN (p): 2319-1805.

[2] Ajinkya Patil, Mrudang Shukla "Implementation of Classroom Attendance System Based on Face Recognition in Class" International Journal of Advances in Engineering \& Technology, July, 2014. IJAET ISSN: 22311963974 Vol. 7, Issue3, pp. 974979.

[3] Jomon Joseph, K.P.Zacharia, "Automated Attendance Management System using Face Recognition", international Journal of Science and Research, Volume 2 Issue 11,November 2013.

[4] Smt.M.P.Satone, Dr.G.K.Kharate, "Face Detection and Recognition in Color Images" IJCSI International Journal of Computer Science Issues, vol.8, Isuue-2, March-2011.

[5] Mrunmayee Shirodkar, Varun Sinha, Urvi Jain, Prof. Bhushan Nemade "Automated Attendance Management System using Face Recognition". International Journal of Computer Application (0975-8887), International Conference and Workshop on Emerging Trends in Technology (ICWET2015).

[6] Balwant Singh, Sunil Kumar, Paurush Bhulania "Lecture Attendance System with Face Recognition and Image Processing". International Journal of Advance Research in Science and Engineering IJARSE.Vol. No.2, Issue No.3, March, 2013.

[7] Rohit Chavan, Baburao Phad, Sankalp Sawant, Vinayak Futak, Asha Rawat "Attendance Management System using Face Recognition". IJIRST-International Journal for Innovative Research in Science \& Technology. Volume 1, Issue 11, April 2015.

[8] Divya Singh, Ruhi Hadke, Shruti Khonde, Valhavi Patil, Monica Kamnani, Mitali Ingle. "Attendance Monitoring using Face Recognition". International Journal of Computer Science and Mobile Computing IJCSMC, Vol.3, Issue 2, February 2014.

[9] Muhammad Fuzail, Hafiz Muhammad Fahad Nouman. Muhammad Omer Mushtaq, Binish Raza Awais Tayyab, Muhammad Waqas Talib. "Face Detection System for Attendance of Class Student". International Journal of Multidisciplinary Sciences and Engineering, Vol.No.5, 4, April 2014.

[10] Moth Moth Myint Thein, Chaw Myat Nweand Hla Myo Tun. "Student Attendance Management System Based On RFID and Fingerprint Reader". International Journal of Scientific \& Technology Research Volume 4, Issue 7, July 2015.

[11] Dayanand S. Shilwant, Dr. A. R. Karwankar. "Student Monitoring by Face Recognition System”. International Jounaral of Electronic, Communication \& Soft Computing Science and Engineering (IJECSCSE) ISSN 2277-9477, Volume 2, Issue 2.

\section{BIOGRAPHIES}

Sneha D. Ikhar is student of Department of Computer Science \& Engineering, Ballarpur Institute of Technology, Ballarsha, Gondwana University Gadhachiroli (MS), India. Her interest in programming languages.

Sagar M. Bhakre is Assistant professor of Department Computer Science \& Engineering, Ballarpur Institute of Technology, Ballarsha, Gondwana University Gadhachiroli (MS), India; he received master degree from JNT University Hyderabad. 